
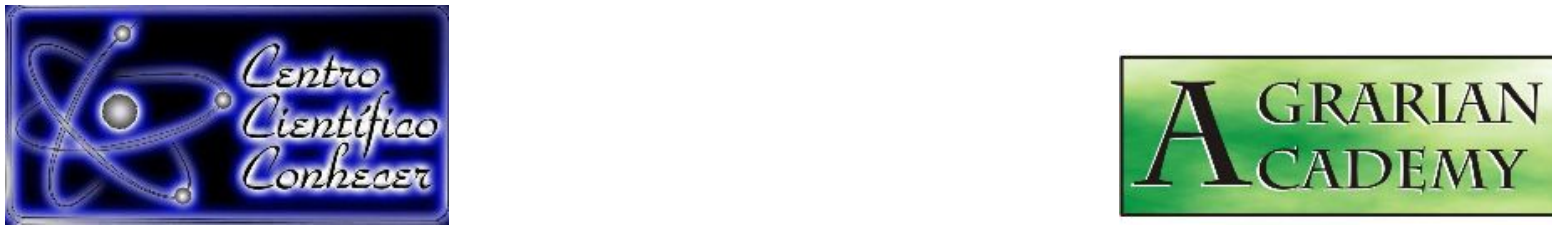

\title{
INTERAÇÃO Allium cepa X Stemphylium spp ASSOCIADOS AO USO DO INDUTOR DE RESISTÊNCIA ACIBENZOLAR S-METIL
}

\footnotetext{
Maria Rita Alves Prudente1; Igor Souza Pereira²; Luciana Santos Rodrigues Costa Pinto $^{3}$

${ }^{1}$ Graduanda em Engenharia Agronômica, Instituto Federal do Triângulo Mineiro campus Uberlândia. Uberlândia, MG, Brasil.

${ }^{2}$ Professor doutor, Instituto Federal do Triângulo Mineiro campus Uberlândia. Uberlândia, MG, Brasil.

${ }^{3}$ Professora doutora, Instituto Federal do Triângulo Mineiro campus Uberlândia. Uberlândia, MG, Brasil. lucianas@iftm.edu.br
}

Recebido em: 19/11/2018 - Aprovado em: 14/12/2018 - Publicado em: 25/12/2018

DOI: 10.18677/Agrarian_Academy_2018B12

Diversos agentes vêm sendo estudados como indutores de respostas de defesa em plantas. Entre esses destaca-se o Acibenzolar S-metil (ASM) que age induzindo a expressão de proteínas PR e enzimas relacionadas com a síntese de lignina como as peroxidases bem como fitoalexinas que são compostos tóxicos aos patógenos, possibilitando aumento da resistência das plantas. Desse modo, objetivou-se estudar o efeito do ASM na manifestação de respostas de defesa a Stemphylium spp. em mudas de cebola, por meio da determinação da atividade da peroxidase. $O$ delineamento experimental utilizado foi o inteiramente casualizado no esquema de parcelas subdivididas no tempo. Foram realizados cinco tratamentos, quatro avaliações no intervalo de 1, 24, 48 e 72 horas após a inoculação do patógeno e quatro repetições. Os tratamentos foram T1 - Testemunha absoluta, T2 - com ASM e sem patógeno, T3 - sem ASM e com patógeno, T4 - com o patógeno e ASM 0,2 $\mathrm{mg} / \mathrm{mL}$ e T5 - com patógeno e ASM 0,4 $\mathrm{mg} / \mathrm{mL}$. Os valores da atividade da enzima peroxidase foram menores, durante os períodos de avaliação, nos tratamentos com ASM ou Stemphylium spp. em comparação com a testemunha. Nos tratamentos com a inoculação do patógeno, independente da presença do ASM a atividade de peroxidase diminuiu ao longo do período de avaliação. Os resultados sugerem que a presença do patógeno é mais efetiva em induzir alterações na atividade enzimática de peroxidase que o ASM, porém somente o comportamento da peroxidase não foi suficiente para entender o seu papel na defesa do vegetal.

PALAVRAS-CHAVE: Bion ${ }^{\circledR}$, cebola, peroxidase.

\section{Allium cepa X Stemphylium spp INTERACTION ASSOCIATED WITH THE USE OF THE RESISTANCE INDUCTOR ACIBENZOLAR S-METHIC}

\section{ABSTRACT}

Several agents have been studied as inducers of defense responses in plants. These include Acibenzolar S-methyl (ASM), which acts to induce the expression of PR 
proteins and enzymes related to lignin synthesis, such as peroxidases, as well as phytoalexins that are compounds toxic to pathogens, thus increasing plant resistance. The aim of this study was to study the effect of ASM on the expression of defense responses to Stemphylium spp. in onion seedlings, by determination of peroxidase activity. The experimental design was completely randomized in split plot in time. Five treatments were performed four ratings in the range of 1, 24, 48 and 72 hours after inoculation of the pathogen and four (4) replicates. Each repetition consisted of 50 seedlings. Treatments T1 - absolute control, T2 - seedlings with ASM and without the pathogen, T3 - no ASM and the pathogen, T4 - with the pathogen ASM and $0.2 \mathrm{mg} / \mathrm{mL}$ and T5 - with the pathogen and ASM $0.4 \mathrm{mg} / \mathrm{mL}$. The amounts of peroxidase enzyme activity were lower during periods of assessment in treatments Stemphylium spp or ASM compared to control treatment (control treatment). In the treatments with inoculation of the pathogen, regardless of ASM presence of peroxidase activity decreased during the evaluation period. The results suggest that the presence of the pathogen is more effective in inducing changes in the enzymatic activity of peroxidase ASM, but only the peroxidase behavior was not enough to understand its role in defending the plant to the experimental conditions described.

KEYWORDS: Bion ${ }^{\circledR}$, onion, peroxidase.

\section{INTRODUÇÃO}

A cebola (Allium cepa), ao lado da batata e do tomate, é considerada uma cultura de grande importância econômica para o Brasil. Cultivada nas regiões Nordeste, Sul, Sudeste e Centro-Oeste, ocupou uma área em torno de 55.000 ha e uma produtividade média de $28.296 \mathrm{~kg} / \mathrm{ha}$ na safra de 2017 . O estado de Minas Gerais destaca-se no cultivo dessa hortaliça, pela elevada produtividade, que pode atingir $100.000 \mathrm{~kg} / \mathrm{ha}$ em determinadas épocas de plantio (IBGE, 2017).

Diante da elevada tecnologia aplicada à cultura na região, observa-se o incremento de doenças capazes de reduzir drasticamente a produtividade (PEREIRA; TEBALDI, 2013). Entre essas doenças pode-se citar a queima-deestenfílio ou mofo-preto causada por Stemphylium spp., que ocasiona frequentes epidemias, conforme registros em inúmeros países (MISHRA; SINGH, 2018). É válido destacar que o ataque dessa doença torna-se mais severo quando associada à mancha-púrpura (Alternaria porri), podendo chegar a $80 \%$ de incidência nas folhas de cebola. No Brasil, o Stemphylium spp., já foi registrado nas culturas de alho e tomate (SUHERI; PRICE, 2000; DOMINGUES et al., 2017).

Apesar do controle químico de doenças se mostrar eficaz, alguns problemas associados vêm sendo constantemente questionados pelo meio científico e pela sociedade, tais como, o desenvolvimento de populações de patógenos insensíveis aos fungicidas em uso, o desequilíbrio ecológico por atingir não somente o patógeno mas, outros organismos (predadores naturais e insetos polinizadores entre outros organismos benéficos), intoxicação do aplicador e do consumidor (FRIEDRICH et al., 2018).

Visando a proteção das plantas sem agredir ao meio ambiente, pesquisas na área de indução de resistência, pelo uso de elicitores se destacam. Compostos elicitores são capazes de ativar mecanismos de defesa de plantas (MOYAELIZONDO; JACOBSEN, 2016) e atualmente a indução de resistência tem sido considerada uma das táticas mais relevantes a serem incorporadas no manejo integrado de doenças, devido tanto ao seu amplo espectro de ação contra fitopatógenos quanto ao baixo impacto ambiental derivado do uso dessa tecnologia. Diversos agentes vêm sendo estudados como possíveis elicitores de respostas de 
defesa ou indutores de resistência com destaque para o indutor de resistência comercial Acibenzolar S-metil (ASM) (ZINE et al., 2016).

Dentre as alterações metabólicas estimuladas pela aplicação de indutores de resistência pode-se destacar a atividade da enzima peroxidase. Alterações na atividade da peroxidase têm sido verificada em vários patossistemas quando se testam agentes patogênicos ou ativadores químicos elicitores (naturais ou sintéticos) para o controle de doenças. As peroxidases participam do processo de lignificação de células vegetais sendo necessárias para a polimerização final de compostos fenólicos junto à lignina. Esta última, por sua vez, pode afetar negativamente o desenvolvimento fúngico, seja através do bloqueio físico, tornando as paredes celulares mais resistentes à penetração mecânica, seja pela diminuição da difusão de nutrientes para o fungo, bem como de toxinas e enzimas fúngicas para a planta (CAVALCANTI et al., 2005).

Partindo dessa premissa, a possibilidade da ativação de mecanismos de resistência, tornando as plantas mais resistentes aos patógenos, abre as portas para estudos envolvendo o fenômeno da indução de resistência, através do uso de indutores comerciais na interação cebola $x$ fungo, visto que podem auxiliar na compreensão do efeito do fungo Stemphylium spp. em processos metabólicos dessas plantas, o que pode proporcionar a descoberta de importantes aspectos práticos e de interesse para a cultura. Dessa forma, pela importância que a cebola apresenta para economia do país e pela severidade dos danos causados pelo fungo Stemphylium spp este trabalho teve como objetivo estudar o efeito do Acibenzolar Smetil (ASM) na manifestação de respostas de defesa a Stemphylium spp, em mudas de cebola, por meio da determinação da atividade da enzima peroxidase.

\section{MATERIAL E MÉTODOS}

O experimento foi conduzido nas dependências do Instituto Federal do Triângulo Mineiro - IFTM - Campus Uberlândia, no município de Uberlândia, Estado

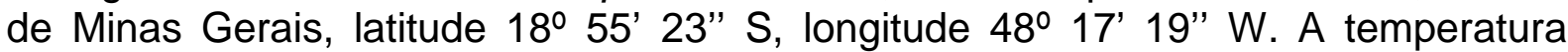
média anual é $22^{\circ} \mathrm{C}$ e a altitude média é de $622 \mathrm{~m}$. Os experimentos foram instalados e conduzidos em casa-de-vegetação e as análises bioquímicas e a manipulação do fungo foram realizadas nos laboratórios de Química e Fitopatologia do IFTM, respectivamente.

\section{Origem, isolamento e preservação do patógeno}

O isolado de Stemphylium sp. utilizado nesse trabalho foi obtido de folhas de cebola cultivar Mercedes ${ }^{\circledR}$, com sintomas típicos da doença, coletadas de uma lavoura comercial situada no município de Santa Juliana, MG. Partes infectadas das folhas foram cortadas em pequenos pedaços com $\pm 1 \mathrm{~cm}^{2}$ cada, lavados em água destilada e esterilizadas pela imersão em hipoclorito de sódio a $0,5 \%$ por dois minutos, em seguida imersos em solução de etanol a 70\% por um minuto e enxaguados três vezes em água esterilizada. Cinco fragmentos foram depositados em placas de Petri ( $9 \mathrm{~cm}$ de diâmetro) contendo $20 \mathrm{~mL}$ do meio batata dextrose ágar (BDA) (SUHERI; PRICE, 2000). Três replicatas foram realizadas para cada amostra.

As placas foram incubadas em câmara climatizada (BOD) a $27^{\circ} \mathrm{C} \pm 2$ e fotoperíodo de $12 \mathrm{~h}$ por 5-6 dias. Os fungos foram purificados pela inoculação em placas de Petri contendo BDA e a identificação dos isolamentos fúngicos foram realizadas com base nas características macro e microscópicas. $O$ isolado puro foi conservado em vidros com água destilada esterilizada para ensaios posteriores. 


\section{Inoculação do fungo}

Para o preparo da suspensão do inóculo, foi feita a adição de $20 \mathrm{~mL}$ de água destilada às placas seguida de leve raspagem com o auxílio de alça de Drigalski para remoção dos conídios. Em seguida a mistura foi filtrada em gaze para a obtenção da suspensão de conídios para a inoculação das mudas de cebola. Após a filtração a concentração da suspensão de conídios para as inoculações foi ajustada para $7,5 \times 10^{4}$ conídios $\mathrm{mL}^{-1}$ em câmara de contagem de Newbauer. As inoculações foram realizadas aos 67 dias após a semeadura e os tratamentos que não receberam a inoculação foram pulverizados com água destilada e em seguida foram colocados à sombra até a secagem.

\section{Determinação da atividade de peroxidase in vivo}

Mudas de cebola, da cultivar Mercedes ${ }^{\circledR}$, foram produzidas em bandejas de 200 células, em condições de casa-de-vegetação onde foram mantidas até o momento das coletas de folhas para a determinação da atividade de peroxidase.

$O$ delineamento experimental utilizado foi o inteiramente casualizado no esquema de parcelas subdivididas no tempo para comparação dos tempos e dos tratamentos. Foram realizados cinco (5) tratamentos, quatro (4) avaliações no intervalo de 1, 24, 48 e 72 horas após a inoculação do patógeno e quatro (4) repetições. Cada repetição foi composta por 50 plantas (mudas).

Os tratamentos foram os seguintes: Tratamento 1 (T1) - testemunha absoluta (sem aplicação do elicitor ASM e não inoculadas); Tratamento 2 (T2) - aplicação do elicitor ASM à $0,4 \mathrm{mg} / \mathrm{mL}$ e não inoculadas; Tratamento 3 (T3) - sem aplicação do elicitor ASM e inoculadas; Tratamento 4 (T4) - aplicação do elicitor ASM à 0,2 mg/mL e inoculadas e Tratamento 5 (T5) - aplicação do elicitor ASM à $0,4 \mathrm{mg} / \mathrm{mL}$ e inoculadas.

Foi utilizado o elicitor de resistência ASM (Acibenzolar S-metil) de marca comercial Bion ${ }^{\circledR} 500$ WG, na formulação de grânulos dispersíveis em água (Bion ${ }^{\circledR}$, Syngenta Proteção e Cultivos Ltda, São Paulo, SP). As concentrações do Bion ${ }^{\circledR}$ usadas nos experimentos foram estabelecidas com base na dosagem recomendada pelo fabricante do produto para outras culturas que há o registro do seu uso. O indutor ASM foi aplicado com auxílio de pulverizador manual em volume suficiente para um completo molhamento foliar das plantas. A aplicação ocorreu duas vezes, com intervalo de uma semana entre elas. A primeira aplicação ocorreu aos 56 dias e a segunda aos 63 dias. Os tratamentos que não receberam o indutor foram pulverizados com água destilada.

Em cada tratamento foram realizadas coletas de tecido foliar fresco para determinação da atividade enzimática de peroxidase. Os dados obtidos foram submetidos a análise de variância para comparação dos tempos e dos tratamentos. Posteriormente foi feito o teste Tukey a $5 \%$ de probabilidade para comparação dos tempos e dos tratamentos dois a dois.

\section{Tempos de coleta para determinação da atividade de peroxidase}

Ao longo do experimento foram realizadas quatro (4) avaliações que ocorreram com 1, 24, 48 e 72 horas após a inoculação do patógeno. O tecido foliar foi coletado com auxílio de um tesoura e rapidamente acondicionado em saquinhos de alumínio devidamente identificados e mantidos no gelo durante todo o período de coleta até o transporte ao laboratório. Em laboratório, as amostras foram congeladas e armazenadas em freezer até o momento das análises. 


\section{Preparo das amostras para determinação da atividade da peroxidase}

O preparo das amostras de tecido foliar de cebola foi feito utilizando a metodologia adaptada de Campos e Silveira (2003). Para tal, as amostras de tecido foliar das quatro (4) avaliações (1, 24, 48 e 72 horas após a inoculação) de cada um dos cinco (5) tratamentos, foram maceradas em almofariz de porcelana contendo solução tampão fosfato $0,05 \mathrm{M}(\mathrm{pH} 7,0)$ na proporção de um grama de amostra (folhas) para $5 \mathrm{~mL}$ de solução tampão $(\mathrm{p} / \mathrm{v})$. Todo o procedimento foi realizado no gelo e os reagentes, tampões e vidrarias também estavam previamente resfriados $\left(4^{\circ} \mathrm{C}\right)$. Após a maceração as amostras foram centrifugadas sob refrigeração a $4000 \mathrm{~g}$. Em seguida o precipitado foi descartado e o sobrenadante foi recolhido, identificado e armazenado em freezer até 0 dia das análises de atividade enzimática. $O$ sobrenadante constituiu o extrato bruto utilizado na análise de atividade enzimática de peroxidase.

\section{Análise enzimática de peroxidase}

A metodologia usada para a análise da atividade enzimática de peroxidase foi adaptada de Campos e Silveira (2003). A solução reativa para a análise da atividade de peroxidase (PO) foi constituída de $1,5 \mathrm{~mL}$ do extrato bruto enzimático ao qual adicionou-se 2,5 mL de tampão fosfato-citrato $(\mathrm{pH} \mathrm{5)} \mathrm{e} 0,25 \mathrm{~mL}$ de solução de guaiacol a $1 \%$ em solução alcoólica a $50 \%$. A solução reativa foi colocada em tubos de ensaio com o auxilio de uma micropipeta de $1000 \mu \mathrm{L}$ e misturadas em vórtex. Em seguida adicionou-se $0,25 \mathrm{~mL}$ de solução de $\mathrm{H}_{2} \mathrm{O}_{2}$ à $3 \%$. Essa solução foi preparada na hora do uso.

A solução reativa foi novamente misturada em vórtex e incubada em banho maria à $30^{\circ} \mathrm{C}$ por 15 minutos. Após a incubação adicionou-se $0,25 \mathrm{~mL}$ de solução de metabissulfito de sódio a $2 \%$, agitou-se novamente a mistura e colocou-se os tubos em gelo por 10 minutos. Em seguida fez-se a leitura de absorbância em espectrofotômetro a $450 \mathrm{~nm}$. A atividade enzimática foi expressa em unidade de enzima (U.E.). Uma unidade de enzima foi definida como a quantidade de extrato enzimático que acusou um aumento na absorbância de 0,001 unidades por minuto. O controle para a reação enzimática (branco) foi feito substituindo-se o volume do extrato enzimático por água destilada na solução reativa.

\section{RESULTADOS E DISCUSSÃO}

As peroxidases estão envolvidas em inúmeros processos fisiológicos na planta, principalmente, no que concerne ao desenvolvimento e amadurecimento. Desse modo, variações na atividade enzimática são de extrema importância, uma vez que irão influenciar a qualidade final dos produtos vegetais.

Analisando a Tabela 1, pode-se perceber variação nos valores da enzima peroxidase na faixa de 21,19 a $82,59 \mathrm{UE} / \mathrm{min} . / \mathrm{g}$ de tecido quando aplicado o tratamento T1 (Testemunha absoluta, sem ASM e o patógeno). Para o tratamento sem o ASM (Bion ${ }^{\circledR}$ ) e com o patógeno (T3) os valores variaram de 30,59 a 64,56 $\mathrm{UE} / \mathrm{min} . \mathrm{g}$ de tecido. 
TABELA 1. Atividade da enzima peroxidase expressa em UE/min./g de tecido foliar de cebola, nos cinco tratamentos em cada período de avaliação. Uberlândia, MG, 2017.

\begin{tabular}{|c|c|c|c|c|}
\hline \multirow{2}{*}{ Tratamentos } & \multicolumn{4}{|c|}{ Períodos de coleta } \\
\hline & 1 hora & 24 horas & 48 horas & 72 horas \\
\hline T1 & 39,78 a B & 21,19 a $B$ & 78,66 a $A$ & 82,59 a $A$ \\
\hline T2 & 30,22 a $A$ & 40,59 a $A$ & 39,70 b $\quad A$ & $37,63 \mathrm{~b} \quad \mathrm{~A}$ \\
\hline T3 & 46,22 a $A B$ & 35,26 a $A B$ & 64,56 ab A & $30,59 \mathrm{bc} \mathrm{B}$ \\
\hline T4 & 30,07 a $A B$ & 28,74 a $A B$ & 59,78 ab A & 23,33 bc $B$ \\
\hline T5 & 29,18 a $A$ & 16,03 a $A B$ & 40,22 b A & 5,91 C B \\
\hline
\end{tabular}

Médias seguidas pela mesma letra minúscula na coluna não diferem estatisticamente entre si pelo teste de Tukey $(>0,05)$. Médias seguidas pela mesma letra maiúscula na linha não diferem estatisticamente entre si pelo teste de Tukey $(>0,05)$.

Os tratamentos com o ASM (Bion ${ }^{\circledR}$ ) e com o patógeno Stemphylium spp (T4 e T5) mostraram valores que variaram de 5,91 a 59,78 UE/min./g de tecido, enquanto que tratamento com o ASM (Bion ${ }^{\circledR}$ ) e sem o patógeno (T2) os valores sofreram as menores variações 30,22 a $40,59 \mathrm{UE} / \mathrm{min} . / \mathrm{g}$ de tecido.

A Tabela 1 mostra ainda que, tratamentos sem o uso do ASM (Bion ${ }^{\circledR}$ ), ou seja, os tratamentos T1 e T3 apresentaram maiores valores da atividade de peroxidase. Já os tratamentos com o ASM $\left(\operatorname{Bion}^{\circledR}\right)$ tanto sem o patógeno (T2) quanto com o patógeno (T4 e T5) apresentaram os menores valores de atividade de peroxidase sendo o $\mathrm{T} 5$, com maior dosagem de ASM $(0,4 \mathrm{mg} / \mathrm{mL})$, o tratamento que apresentou o menor valor de atividade da enzima peroxidase, ou seja, 5,91 $\mathrm{UE} / \mathrm{min} . / \mathrm{g}$ de tecido. Os valores da atividade de peroxidase sofreram alterações em todos os tratamentos nos quatro períodos de coleta (Tabela 2).

TABELA 2. Médias totais de atividade de peroxidase (UE/min./g de tecido) nas folhas de mudas de cebola em cada tratamento. Uberlândia, MG, 2017.

\begin{tabular}{cc}
\hline Tratamentos & Médias dos Tratamentos \\
\hline T1 & $55,55 \mathrm{a}$ \\
T2 & $37,04 \mathrm{ab}$ \\
T3 & $44,16 \mathrm{a}$ \\
T4 & $35,48 \mathrm{ab}$ \\
T5 & $22,84 \mathrm{~b}$ \\
\hline
\end{tabular}

Médias seguidas pela mesma letra na coluna não diferem estatisticamente entre si pelo teste de Tukey $(>0,05)$.

Comparando os tratamentos, verificou-se que os tratamentos T1 e T3 (sem o ASM) foram estatisticamente diferentes do tratamento 5 (T5), com a maior dosagem de ASM. Em relação aos demais tratamentos, não houve diferença.

A Tabela 3 mostra os valores da atividade de peroxidase em UE/min./g de tecido, nas folhas de mudas de cebola dentro de cada um dos quatro períodos de avaliação, ou seja, 1, 24, 48 e 72 horas após a inoculação, independente do tratamento. 
TABELA 3. Médias totais de atividade de peroxidase (UE/min./g de tecido) nas folhas de mudas de cebola dentro de cada período de avaliação (tempo). Uberlândia, MG, 2017.

\begin{tabular}{cc}
\hline Tempos & Médias dos Tempos \\
\hline 1 hora & $35,09 \mathrm{~b}$ \\
24 horas & $28,36 \mathrm{~b}$ \\
48 horas & $56,58 \mathrm{a}$ \\
72 horas & $36,01 \mathrm{~b}$ \\
\hline
\end{tabular}

Médias seguidas pela mesma letra na coluna não diferem estatisticamente entre si pelo teste de Tukey $(>0,05)$.

Comparando os tempos, verificou-se que a atividade de peroxidase no tempo de $48 \mathrm{~h}$ foi maior que os demais tempos (Tabela 3). Fazendo a comparação de cada tratamento dentro dos tempos (Tabela 1), verificou-se que não houve diferença significativa nos tempos de uma hora e 24 horas. No tempo de 48 horas, o T1 apresentou a maior quantidade e diferiu estatisticamente de T2 e T5, porém, não diferiu estatisticamente de T3 e T4. Os tratamentos T2 e T5 apresentaram as menores médias, porém não foram estatisticamente diferentes de T3 e T4. No período de 72 horas, o T1 apresentou a maior média e diferiu estatisticamente dos demais. O T5 foi o que apresentou a menor média, porém não diferiu estatisticamente de T3 e T4.

Para a melhor discussão dos resultados obtidos, os valores de atividade de peroxidase (UE/min./g de tecido) nas folhas de mudas de cebola mostrados nas tabelas 1, 2 e 3 serão representados graficamente na Figura 1. O Acibenzolar SMetil (ASM) é um análogo do ácido salicílico, que age induzindo a ativação de genes que codificam proteínas PR e enzimas relacionadas com a síntese de lignina e fitoalexinas que são compostos tóxicos aos patógenos, possibilitando aumento da resistência das plantas. Vários trabalhos demonstraram a utilização de produtos comerciais com ASM para promover a ativação da resistência de culturas economicamente importantes, como trigo (MOYA-ELIZONDO; JACOBSEN, 2016), café (GUIMARÃES et al., 2016) e feijoeiro (KUHN; PASCHOLATI, 2010).

$\mathrm{Na}$ indução de resistência, as peroxidases são bastante estudadas devido à sua importância nos processos de defesa e conforme afirmam Kofalvi e Nassuth (1995) o aumento da atividade de peroxidases é observado quando ocorre uma infecção e o interesse maior no estudo das peroxidases envolve o papel que elas desempenham na restrição de um patógeno. 


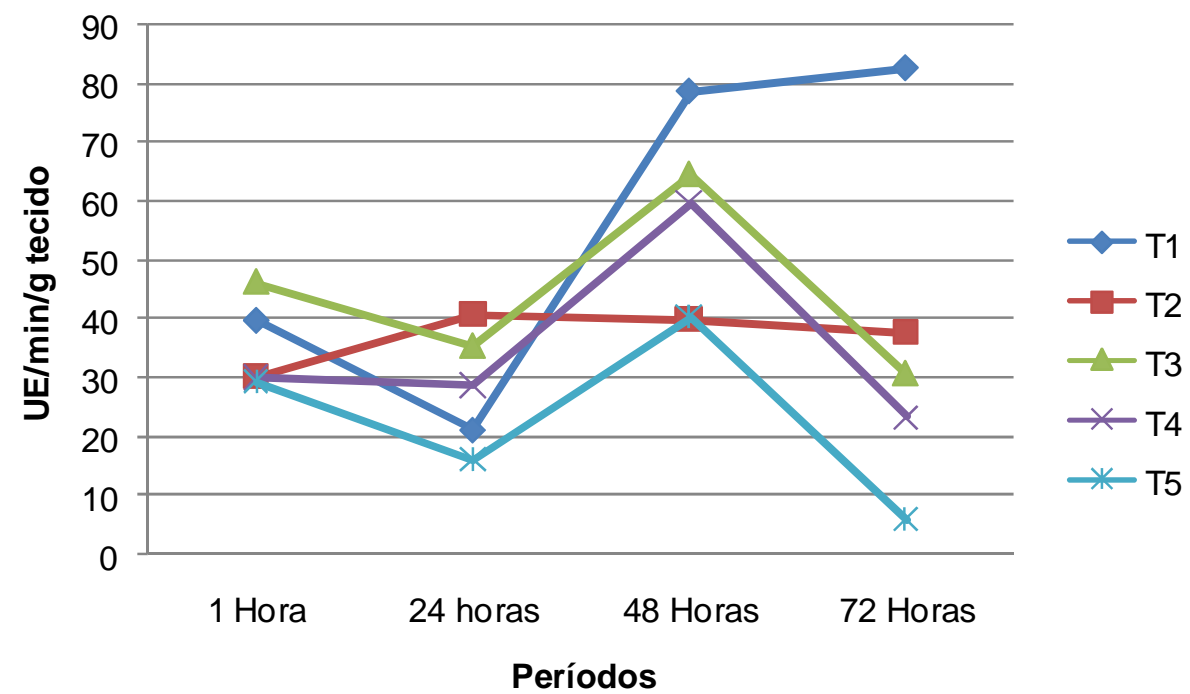

FIGURA 1. Comportamento da atividade da enzima peroxidase dos cinco tratamentos nos diferentes períodos avaliados. Uberlândia, MG, 2017.

Apesar dos inúmeros trabalhos que apontam uma estreita correlação no uso de indutores de resistência como o ASM, com aumentos na atividade da peroxidase, os resultados mostrados na Figura 1 sugerem que, para mudas de cebola nas condições do experimento descrito, esse comportamento não é o observado.

Pode-se verificar pela Figura 1 que no tratamento controle, ou seja, o T1 (testemunha absoluta), onde as mudas crescem tanto sem a aplicação do ASM quanto do patógeno os valores da atividade de peroxidase são mais elevados quando comparados com os demais tratamentos (Tabelas 1, 2, 3 e Figura 1). Tal resultado indica que, em mudas de cebola os valores de atividade de peroxidase já são elevados, independente da presença de Stemphylium spp. ou ASM.

Isso pode ser explicado pelo desenvolvimento normal das mudas, pois de acordo com Oliveira et al. (2001) as peroxidases estão diretamente envolvidas no processo de lignificação da parede celular. Considerando que à medida que avança o processo de crescimento e desenvolvimento (germinação a senescência), os vegetais passam de mais tenros a mais lignificados, esse comportamento é esperado nas mudas de cebola desse tratamento. Assim, esse maior valor de atividade de peroxidase no tratamento controle (T1) pode estar dentro do esperado para as mudas de cebola nas condições experimentais tratadas.

Ainda analisando a Figura 1 verifica-se que os tratamentos que apresentam tanto o patógeno Stemphylium spp (T3) quanto apenas o ASM (T2) e ainda o ASM e o patógeno (T4 e T5), ou seja, tratamentos com indutores bióticos, abióticos (químicos) ou ambos (bióticos e abióticos), os valores de atividade de peroxidase diminuíram ao longo do período de avaliação quando comparados com o T1. Contudo, nos tratamentos com a inoculação do patógeno (T3, T4 e T5) essa queda nos valores de atividade de peroxidase foram maiores do que para o tratamento com o ASM e sem a inoculação do patógeno (T2), onde pode ser visto pela Figura 1, que os valores de atividade de peroxidase permaneceram praticamente constantes.

Pode-se afirmar que, as folhas de mudas de cebola, nos tratamentos sem inoculação do patógeno e, sem e com a aplicação do indutor (ASM), ou seja, T1 e T2 respectivamente tiveram as atividades de peroxidase aumentadas ao longo do 
período de avaliação. Já os tratamentos com a inoculação do patógeno e, sem a aplicação do ASM (T3) ou com a aplicação do ASM (T4 e T5) a atividade de peroxidase diminuiu ao longo do período de avaliação, sugerindo que a presença do patógeno Stemphylium spp é mais efetiva em induzir variações na atividade enzimática de peroxidase que o ASM. É importante ressaltar que o ASM (Bion ${ }^{\circledR}$ ) não é um produto indicado como indutor de resistência para a cultura de cebola conforme dados do fabricante (Syngenta Produção de Cultivos Ltda, São Paulo).

Em plantas de pepino as peroxidases não têm relação direta com a resistência sistêmica adquirida (RSA) e, portanto, não podem ser usadas como um marcador de resistência. Embora as peroxidases não possam ser utilizadas como marcadores de resistência, a alteração na atividade é um indício de metabolismo alterado. A alteração de metabolismo em organismos vivos raramente é pontual, já que as diversas rotas metabólicas interagem (NUNES JR et al., 2017).

De acordo com Soares (2014) o indutor Bion ${ }^{\circledR}$ (ASM) não foi eficiente na promoção da resistência contra $P$. carotovorum e a avaliação da atividade das enzimas peroxidase e polifenoloxidase não foi eficiente para indicar características de defesa nas plantas de $S$. tuberosum cultivadas in vitro.

Se a modificação na atividade de uma enzima é um indício de metabolismo alterado, a compreensão do modo como as rotas metabólicas interagem é fundamental para entender as diferentes respostas dos diferentes mecanismos de resistência dos vegetais. Uma das funções das peroxidases é a formação da lignina pela polimerização de fenóis. Assim sendo, é esperado que alterações na atividade de peroxidases envolvam também alteração na atividade de outras enzimas presentes na mesma rota metabólica. Devido a estes fatos, as peroxidases são usadas em estudos de indução de resistência, não como um marcador, mas sim como uma das muitas respostas de defesa manifestadas pelas plantas (PASSARDI et al., 2005).

O metabolismo secundário vegetal possui papel importante na adaptação do vegetal ao meio em que vive. É também importante na interação das plantas com outros organismos, tais como insetos e microrganismos, patogênicos ou não, onde poderão atuar na produção de compostos diretamente ligados à promoção da defesa vegetal (NUNES JR et al., 2017).

A peroxidase parece ser a molécula chave de adaptação das plantas, ou de algum de seus órgãos separadamente, às mudanças do meio ambiente. A indução da atividade da peroxidase pode ser um mecanismo utilizado pelos vegetais para reduzir os níveis de $\mathrm{H}_{2} \mathrm{O}_{2}$ e peróxidos orgânicos formados sob diferentes condições de estresse (BARBOSA et al., 2014). Esta enzima tem sido amplamente estudada em plantas e empregada em uma variedade de processos fisiológicos incluindo a biossíntese da lignina, polimerização e cicatrização de ferimentos (CHEN; VIERLING, 2000).

Em condições de estresse, as plantas tendem a aumentar a atividade da peroxidase e às vezes, é a primeira enzima a ter atividade alterada, independentemente do substrato utilizado ou do estresse aplicado. Assim, a peroxidase pode ser tomada como um marcador bioquímico de estresse resultante tanto de fatores bióticos como de abióticos (BARBOSA et al., 2014). Os resultados apresentados sobre a atividade da enzima peroxidase em mudas de cebola não permitem relacionar o seu papel na defesa do vegetal mas pode-se afirmar que indutores bióticos e abióticos alteram a atividade de peroxidase. 


\section{CONCLUSÕES}

Os valores da atividade da enzima peroxidase em folhas de mudas de cebola foram menores, durante os períodos de avaliação, nos tratamentos com indutores bióticos (Stemphylium spp) ou abióticos (ASM) em comparação com o tratamento controle para as condições experimentais descritas.

Nos tratamentos sem a inoculação do patógeno e sem e com a aplicação do ASM, as atividades de peroxidase aumentaram ao longo do período de avaliação.

Os tratamentos com a inoculação do patógeno e, sem a aplicação do ASM (T3) ou com a aplicação do ASM (T4 e T5) a atividade de peroxidase diminuiu ao longo do período de avaliação.

Os resultados sugerem que, em mudas de cebola, nas condições experimentais testadas, a presença do patógeno é mais efetiva em induzir variações na atividade enzimática de peroxidase que o ASM, porém somente a avaliação do comportamento da atividade da enzima peroxidase não foi suficiente para entender o seu papel na defesa do vegetal em resposta a estresses bióticos e abióticos.

\section{REFERÊNCIAS}

BARBOSA, M. R.; SILVA, M. M. de A.; ULISSES, L. W. C.; CAMARA, T. R. Geração e desintoxicação enzimática de espécies reativas de oxigênio em plantas. Ciência Rural, v. 44, p. 453-460, 2014. Disponível em: <http://dx.doi.org/10.1590/S010384782014000300011 >. doi: 10.1590/S0103-84782014000300011.

CAMPOS, A. D; SILVEIRA, E. M. L. Metodologia para determinação da peroxidase e da polifenoloxidase em plantas. EMBRAPA: Comunicado Técnico 87, 2003, 3p. Disponível em: <https://www.infoteca.cnptia.embrapa.br/bitstream/doc/744473/1/comunicado87.pdf>

CAVALCANTI, L. S.; BRUNELLI, K. R.; STANGARLIN, J. R. Aspectos bioquímicos e moleculares da resistência induzida. In: CAVALCANTI, L. S.; DI PIERO, R. M.; CIA, P.; PASCHOLATI, S. F.; RESENDE, M. L. V.; ROMEIRO, R. S. Indução de resistência em plantas a patógenos e insetos. Piracicaba: FEALQ, 2005. cap. 4. p.81-124.

CHEN, H.; VIERLING, R. A. Molecular cloning an characterization of soybean peroxidase genes families. Plant Science, v. 150, n. 2, p. 129-137, 2000. Disponível em:<https://doi.org/10.1016/S0168-9452(99)00165-X>. doi: 10.1016/S01689452(99)00165-X.

DOMINGUES, D. P.; SANTOS, C. A.; KOWATA-DRESCH, L. S.; CARMO, M. G. F. Quantificação e progresso da mancha-de-estenfílio em cultivares de tomate sob manejo orgânico. Caderno de Ciências Agrárias, [S.I.], v. 9, n. 1, p. 09-18, abr. 2017. Disponível em: <https://seer.ufmg.br/index.php/ccaufmg/article/view/3950>.

FRIEDRICH, K.; de ALMEIDA, V. E. S.; AUGUSTO, L. G. S.; GURGEL, A. M.; de SOUZA, V. .M O.; ALEXANDRE, V. P.; CARNEIRO, F. F. Agrotóxicos: mais venenos em tempos de retrocessos de direitos. Revista OKARA: Geografia em debate, v.12, n.2, p. 326-347, 2018. Disponível em: <http://www.periodicos.ufpb.br/index.php/okara/article/view/41320/20726>. 
GUIMARÃES, S. E.; RESENDE, M. L. V.; SANTOS, D. M.; MONTEIRO, A. C. A.; VASCONCELOS, V. A. M.; SILVA, JÚNIOR M. B. Indutores de resistência no controle da cercosporiose do cafeeiro: análise de genes relacionados à defesa. Coffee Science, Lavras, v. 11, n. 3, p. 308 - 317, jul./set. 2016. Disponível em: <http://dx.doi.org/10.25186/cs.v11i3.1071>. doi: 10.25186/cs.v11i3.1071.

IBGE - Instituto Brasileiro de Geografia e Estatistica. Levantamento Sistemático da Produção Agrícola. Rio de Janeiro: IBGE. v. 30, n. 1, 81 p., 2017. Disponível em:

$\mathrm{ftp}: / /$ ftp.ibge.gov.br/Producao_Agricola/Levantamento_Sistematico_da_Producao_Ag ricola_[mensal]/Fasciculo/2017/lspa_201701.pdf>.

KOFALVI, S. A.; NASSUTH, A. Influence of wheat streak mosaic virus infection on phenylpropanoid metabolism and the accumulation of phenolics and lignin in wheat. Physiological and Molecular Plant Pathology, v. 47, n.06, p. 365-377, 1995. Disponível em: <https://doi.org/10.1006/pmpp.1995.1065>. 10.1006/pmpp.1995.1065.

KUHN, O. J.; PASCHOLATI, S. F. Custo adaptativo da indução de resistência em feijoeiro mediada pela rizobactéria Bacillus cereus ou acibenzolar- S- metil: atividade de enzimas, síntese de fenóis e lignina e biomassa. Summa Phytopathologia, Jaguariúna, v. 36, n. 2, p. 107-114, 2010. Disponível em: <http://dx.doi.org/10.1590/S0100-54052010000200001>. doi: 10.1590/S010054052010000200001.

MISHRA, B.; SINGH, R. Spray scheduling of fungicide Difenoconazole 25EC for the management of Stemphylium blight of onion (Allium cepa L.). Journal of Applied and Natural Science, v.10, n.3, p. 971-975, 2018. Disponível em: <https://doi.org/10.31018/jans.v10i3.1829>. doi: 10.31018/jans.v10i3.1829.

MOYA-ELIZONDO, E. A., JACOBSEN, B. J. Integrated management of Fusarium crown rot of wheat using fungicide seed treatment, cultivar resistance, and induction of systemic acquired resistance (SAR). Biological Control, v. 92, n. 1, p. 153-163, 2016. Disponível em: <https://doi.org/10.1016/j.biocontrol.2015.10.006>. doi: 10.1016/j.biocontrol.2015.10.006.

NUNES JR., F. H.; GONDIM, F. A.; FREITAS, V. S.; BRAGA, B. B.; BRITO, P. O. B.; MARTINS, K. Crescimento foliar e atividades das enzimas antioxidativas em plântulas de girassol suplementadas com percolado de aterro sanitário e submetidas a estresse hídrico. Revista Ambiente e Água Taubaté, vol. 12, n. 1, p. 71-86, 2017. Disponível em: <http://dx.doi.org/10.4136/ambi-agua.1964>. doi: 10.4136/ambiagua.1964.

OliVEIRA, J. T. A., ANDRADE, N. C., MIRANDA, A. S. M., BARRETO, A. L. H., MELO, V. M. M., FERNANDES, C. F., VASCONCELOS, I. M., SILVEIRA, J. A. G., CAVALCANTI, F. R., FREIRE-FILHO, F. R., FREIRE, F. C. O.; GONÇALVES, F. J. T. Atividades peroxidásica e $\beta-1,3$ glucanásica elicitadas por agentes bióticos causadores de doenças e pelo estresse hídrico em feijão-de-corda (Vigna unguiculata (L.) Walp.). Anais da V Reunião Nacional de Pesquisa de Caupi-V RENAC, Teresina, PE. p. 19-23, 2001. 
PASSARDI, F.; COSIO, C.; PENEL, C.; DUNAND, C. Peroxidases have more functions than a Swiss army knife. Plant cell reports, v. 24, n. 5, p. 255-265, 2005. Doi: 10.1007/s00299-005-0972-6.

PEREIRA, I. S.; TEBALDI, N. D. Occurrence of Xanthomonas axonopodis pv. allii causing onion bacterial blight in Minas Gerais State, Brazil. Summa Phytopathologica, v. 39, p. 297-297, 2013. Disponível em: <http://dx.doi.org/10.1590/S0100-54052013000400015>. doi: 10.1590/S010054052013000400015.

SOARES, N. R. Processos celulares envolvidos nas respostas de defesa de Solanum tuberosum L. contra Pectobacterium carotovorum. 2014. $51 \mathrm{f}$. Dissertação (Mestrado em Biologia Celular e Molecular) - Pontifícia Universidade Católica do Rio Grande do Sul, Porto Alegre, 2014. Disponível em: $<$ http://tede2.pucrs.br/tede2/handle/tede/5500>.

SUHERI, H; PRICE, T. V. Infection of onion leaves by Alternaria porri and Stemphylium vesicarium and disease development in controlled environments. Plant Pahtology, v.49, p. 375-382, 2000. Disponível em: <https://doi.org/10.1046/j.13653059.2000.00458.x>. doi: 10.1046/j.1365-3059.2000.00458.x.

ZINE, H.; RIFAI, L. A.; FAIZE, M.; SMAILI, A.; MAKROUM, K.; BELFAIZA, M.; KABIL, EL M.; KOUSSA, T. Duality of acibenzolar-S-methyl in the inhibition of pathogen growth and induction of resistance during the interaction tomato/Vertcillium dahliae. European Journal of Plant Pathology, v. 145, n. 1, p. 61-69. 2016. Disponível em: <https://doi.org/10.1007/s10658-015-0813-6>. doi: 10.1007/s10658015-0813-6. 